\title{
The use of national administrative data to describe the spatial distribution of in-hospital mortality following stroke in France, 2008-2011
}

\author{
Adrien Roussot ${ }^{1,2}$, Jonathan Cottenet ${ }^{1,2}$, Maryse Gadreau ${ }^{3}$, Maurice Giroud ${ }^{4}$, Yannick Béjot ${ }^{4}$ \\ and Catherine Quantin ${ }^{1,2,5,6,7^{*}}$
}

\begin{abstract}
Background: In the context of implementing the National Stroke Plan in France, a spatial approach was used to measure inequalities in this disease. Using the national PMSI-MCO databases, we analyzed the in-hospital prevalence of stroke and established a map of in-hospital mortality rates with regard to the socio-demographic structure of the country.

Methods: The principal characteristics of patients identified according to ICD10 codes relative to stroke (in accordance with earlier validation work) were studied. A map of standardized mortality rates at the level of PMSI geographic codes was established. An exploratory analysis (principal component analysis followed by ascending hierarchical classification) using INSEE socio-economic data and mortality rates was also carried out to identify different area profiles.

Results: Between 2008 and 2011, the number of stroke patients increased by $3.85 \%$, notably for ischemic stroke in the 36-55 years age group ( $60 \%$ of men). Over the same period, in-hospital mortality fell, and the map of standardized rates illustrated the diagonal of high mortality extending from the north-east to the south-west of the country. The most severely affected areas were also those with the least favorable socio-professional indicators.

Conclusions: The PMSI-MCO database is a major source of data on the health status of the population. It can be used for the area-by-area observation of the performance of certain healthcare indicators, such as in-hospital mortality, or to follow the implementation of the National Stroke Plan. Our study showed the interplay between social and demographic factors and stroke-related in-hospital mortality. The map derived from the results of the exploratory analysis illustrated a variety of areas where social difficulties, aging and high mortality seemed to meet. The study raises questions about access to neuro-vascular care in isolated areas and in those in demographic decline. Telemedicine appears to be the solution favored by decision makers. The aging of the population managed for stroke must not mask the growing incidence in younger people, which raises questions about the development of classical (smoking, hypertension) or new (drug abuse) risk factors.
\end{abstract}

Keywords: PMSI, Stroke, Geography, In-hospital mortality

\section{Background}

The management of stroke is becoming an increasingly heavy burden worldwide for both developed and developing countries. Though the incidence rate of the disease

\footnotetext{
*Correspondence: catherine.quantin@chu-dijon.fr

${ }^{7}$ Biostatistics, Biomathematics, Pharmacoepidemiology and Infectious Diseases (B2PHI), Univ. Bourgogne Franche-Comté, Inserm UMR 1181, Dijon 21000, France

Full list of author information is available at the end of the article
}

in rich countries has fallen over the last 20 years, prevalence has increased as the quality of stroke management has improved $[1,2]$. It is becoming necessary to evaluate responses provided by healthcare systems and then to implement public healthcare actions to cope with the burden of this disease in both the acute and chronic phase.

Since the year 2000, France has been engaged in a battle against stroke, and since 2010, all of the actions in the 
management of stroke patients have been incorporated in a "2010-2014 National Stroke Action Plan" [3]. This plan, which was based on a comprehensive 'inventory' requested by the Ministry of Health and which associated researchers, the relevant learned societies and representatives of patients [4], emphasizes the need for a territory-wide stroke-care network. At the regional level, emergency stroke management is centered on stroke units and better coordination between these establishments and follow-up care and rehabilitation departments in the downstream management of stroke.

The national strategy in the fight against stroke also involves the development of epidemiological research in stroke, notably through the increased exploitation of existing information systems: PMSI-MCO (Programme de médicalisation des systèmes d'information) and SNIIR-AM (Système national inter-régime de l'assurance maladie) (action 8 of the Plan). Indeed, a number of studies have been conducted thanks to the availability and long-standing nature of medico-administrative databases. The PMSI-MCO in particular is a precious source of information for studies in epidemiology [5] or healthcare economics [6]. Indeed, the PMSI is the main source of French hospitalisation data. For each patient, it gathers all of the hospital stays during the year and allows patients to be followed over time thanks to a unique data linkage number.

Earlier studies on the incidence and prevalence of stroke conducted using the PMSI-MCO showed that the demographics of the population managed for stroke have changed over the last 20 years. This situation is probably related to the greater efficacy of prevention messages and the earlier involvement of the healthcare system. A study published in 2012 [7] underlined the interest of the PMSI-MCO to elaborate and analyze hospital and follow-up care trajectories. The study highlighted the growing importance of stroke units between 2007 and 2009 and concluded that the overall management of stroke was more effective, with a reduction of the in-hospitality mortality.

This work is a continuation of these observational studies on the results of care in stroke patients, in the context of the deployment of the National Action Plan. In this context, we can make the hypothesis that this decrease may be observable for a larger period and that its spatial distribution in France follows an heterogenic organization. We studied the number of stroke victims at the national level in France between 2008 and 2011 using PMSI-MCO medico-administrative databases, as well as the evolution of the principal characteristics of this population, notably with regard to in-hospital mortality. The analysis presents a map of in-hospital mortality, as well as an exploratory analysis of the territorial distribution of this mortality with regard to demographic and socioeconomic data.

The aim of this analysis was to describe the spatial distribution of in-hospital mortality related to the socio-economic characteristics of the patients' places of residence.

\section{Methods}

\section{Source of data and selection criteria}

Given the lack of long-term data in the national PMSI databases and the absence of accurate coding to distinguish between first-ever and recurrent stroke, this study analyses the characteristics of patients hospitalized for stroke rather than the in-hospital incidence.

The algorithm used was the same as that used for other French studies conducted using the national PMSI database. All of the hospital stays for patients presenting with a diagnosis of stroke recorded in the national PMSIMCO databases from 2008 to 2011, whatever their age, were included. The hospital stays were selected according to the principal diagnosis (PD) according to the following ICD10 codes:

- I60, I61, I62.9 for hemorrhagic stroke.

- I63, I64, G46 for ischemic stroke.

In our selection process, we chose to keep patients with a "transfer" admission, that is to say patients who stayed first in one establishment and then moved to a second establishment with a PD of stroke. In these cases of transfer, only the second stay with a diagnosis of stroke was taken into account for the analysis. All hospital stays ending with in-hospital death (discharge code $=9$ ) were included, even when the hospital stay was 0 days. For deceased patients who had accumulated several hospital stays after a stroke, their death was identified in a period of 30 days following the first hospital stay for stroke. For patients who were transferred during their management, the complete duration of the hospital stay was taken into account.

Selection was limited to geographical codes for France. PMSI geographic codes indicate where patients live; in France these places correspond to zip codes. Hospital stays presenting coding errors shown by a return code or an error in the DRG (Diagnosis Related Group) code were removed.

\section{Calculation of standardized in-hospital mortality rates}

The mortality rate included all of the in-hospital deaths recorded during the period of the study (2008-2011). It was standardized for age according to the direct method, by using as the reference INSEE (Institut National de la Statistique et des Etudes Economiques: French national census institute data of the 2009 population census at the 
level of the PMSI geographic code for the place of residence. These population data were obtained by aggregation of the census data available for each town using the post code and the corresponding PMSI geographic code established by the ATIH (Agence Technique de l'Information Hospitalière: Technical agency for hospital information) in 2010. Mortality rates are expressed for 100,000 inhabitants. The exploratory analysis is based on commune-by-commune INSEE data for Employed persons-active Population from the 2011 census and aggregated according to the post code and PMSI geographic code.

\section{Exploratory analysis: typology of the territories according to their socio-economic and demographic structure related to in-hospital mortality}

- The exploratory analysis consisted of a principal components analysis (PCA) followed by an ascending hierarchical classification (AHC) using Ward's step method bearing on several variables of interest at the level of the 5672 PMSI geographic codes of their residence in France. The ascending hierarchical classification (AHC) consisted in gradually aggregating the geographic codes according to their resemblance, which allowed us to predict the cluster of an individual according to the values taken by the predictive variables: Proportion of each occupational category in the active population

- Proportion of unemployed people in the active population

- Proportion of retired or pre-retired people aged 15-64 in the active population

- Proportion of the whole population aged less than 20 years

- Proportion of the whole population aged from 20 to 59 years

- Proportion of the whole population aged more than 60 years

- Standardized rate of in-hospital mortality due to stroke for 100,000 inhabitants

We kept the first three factorial axes from the PCA for the AHC. These allowed us to synthesize $69.2 \%$ of the information. All of the variables selected in the AHC were discriminating for the description and the construction of the different clusters of PMSI geographic areas (cf. Table 5). Only the managers or professional occupations category (SPC $n^{\circ} 3$ ) was not retained to describe cluster 4 ( $\mathrm{p}>0.05)$. The typology from the AHC was based on 5 classes of affectation for the geographic codes. This apportionment was obtained after interpretation of the associated dendogram, from the cubic clustering criterion (measures the quality of the cluster) and from the semi-partial $R^{2}$ (measures the loss of interclass inertia). The results obtained from the classification are presented in Tables 5 and 6, which present the means of each variable within the clusters, as well as their discriminating power $(\mathrm{p}<0.05)$ for the construction of each cluster. The cartographic results concerning the classification of geographic codes of the place of residence are shown in Fig. 5. For each variable, the legend presents the mean deviation, calculated overall for the geographic codes of the place of residence. The bars on the right of the vertical line represent a positive delta, while those on the left represent a negative delta. The wider the bar, the greater the mean deviation (positive or negative) is.

The description of each cluster can be determined in a complementary manner from Fig. 5, Tables 5 and 6.

SAS 9.3 software was used for all of the analyses. GIS (Geographic Information System) MapInfo 11.0 was used for the cartography.

\section{Results}

\section{Hospitalizations for AVC: characteristics of the study} population

In France, the number of people hospitalized for stroke increased by $3.9 \%$, from 96,695 to 100,420 between 2008 and 2011 (c.f. Table 1). There was, however, a slight fall in the number of patients between 2010 and 2011 (fall of 1295 cases). In detail, the greatest increase concerned ischemic stroke (+3.9\%); the number of patients hospitalized for hemorrhagic stroke increased by $3.3 \%$.

From 2008 to 2011, 97,574 people were hospitalized for stroke in France, 22,327 (22.8 \%) presented hemorrhagic stroke and 75,247 (77.2 \%) ischemic stroke. The distribution according to the year was stable (Table 1).

More women than men were hospitalized for stroke [203,467 (50.8\%) vs. 197,335 (49.2\%) for the whole period] and whatever the year. The differences between the years were not significant (Table 1). The percentage of women hospitalized for hemorrhagic stroke (51.2\%-Table 2) was greater than that for ischemic stroke (50.6\%-Table 3). The difference was significant $(p=0.0067)$. In addition, for hemorrhagic stroke (Table 2), the proportion of women hospitalized increased between 2008 (50.7 \%) and 2011 (51.6 \%), the difference was significant (Somers'd $=0.0452$ ).

For all strokes (Table 1), we found an increase in the proportion of people older than 55 hospitalized for stroke from $85.7 \%$ in 2008 to $86.2 \%$ in 2011. The difference was significant (Somers'd $=0.0106$ ). This significant increase occurred in women $(88.0 \%$ in 2008 vs $88.6 \%$ in 2011 : Somers'd $=0.0013$ ) but not in men (Table 1). This global trend was related (Table 2) to the substantial increase in the proportion of patients older than 55 years hospitalized for hemorrhagic stroke $(76.3 \%$ in 2008 vs $78.5 \%$ in 
Table 1 Global description of strokes

\begin{tabular}{|c|c|c|c|c|c|c|c|c|c|c|c|c|}
\hline \multirow[t]{2}{*}{ Strokes } & \multicolumn{2}{|l|}{2008} & \multicolumn{2}{|l|}{2009} & \multicolumn{2}{|l|}{2010} & \multicolumn{2}{|l|}{2011} & \multicolumn{2}{|l|}{ Total } & \multirow{2}{*}{$\begin{array}{l}x^{2} \\
p\end{array}$} & \multirow{2}{*}{$\begin{array}{l}\text { Somers'd } \\
\text { p }\end{array}$} \\
\hline & $\mathbf{n}$ & $\%$ & $n$ & $\%$ & $\mathrm{n}$ & $\%$ & $\mathbf{n}$ & $\%$ & $\mathrm{n}$ & $\%$ & & \\
\hline All strokes & 97,574 & & 99,398 & & 102,593 & & 101,237 & & 400,802 & & & \\
\hline Hemorrhagic & 22,327 & 22.9 & 22,618 & 22.7 & 23,426 & 22.8 & 23,056 & 22.8 & 91,427 & 22.8 & NS & NS \\
\hline Ischemic & 75,247 & 77.1 & 76,780 & 77.3 & 79,167 & 77.2 & 78,181 & 77.2 & 309,375 & 77.2 & & \\
\hline \multicolumn{13}{|l|}{ Age } \\
\hline \multicolumn{13}{|l|}{ All patients } \\
\hline$\leq 35$ & 2476 & 2.5 & 2491 & 2.5 & 2586 & 2.5 & 2310 & 2.3 & 9863 & 2.5 & 0.0005 & 0.0106 \\
\hline $36-55$ & 11,464 & 11.8 & 11,395 & 11.5 & 12,017 & 11.7 & 11,706 & 11.6 & 46,582 & 11.6 & & \\
\hline$>55$ & 83,634 & 85.7 & 85,512 & 86.0 & 87,990 & 85.8 & 87,221 & 86.2 & 344,357 & 85.9 & & \\
\hline \multicolumn{13}{|l|}{ Male } \\
\hline$\leq 35$ & 1220 & 2.5 & 1202 & 2.5 & 1332 & 2.6 & 1127 & 2.3 & 4881 & 2.5 & 0.0058 & NS \\
\hline $36-55$ & 6786 & 14.1 & 6728 & 13.8 & 7069 & 14.0 & 7044 & 14.1 & 27,627 & 14.0 & & \\
\hline$>55$ & 40,255 & 83.4 & 40,867 & 83.8 & 42,061 & 83.4 & 41,644 & 83.6 & 164,827 & 83.5 & & \\
\hline \multicolumn{13}{|l|}{ Female } \\
\hline$\leq 35$ & 1256 & 2.6 & 1289 & 2.6 & 1254 & 2.4 & 1183 & 2.3 & 4982 & 2.5 & 0.0074 & 0.0013 \\
\hline $36-55$ & 4678 & 9.5 & 4667 & 9.2 & 4948 & 9.5 & 4662 & 9.1 & 18,955 & 9.3 & & \\
\hline$>55$ & 43,379 & 88.0 & 44,645 & 88.2 & 45,929 & 88.1 & 45,577 & 88.6 & 179,530 & 88.2 & & \\
\hline \multicolumn{13}{|l|}{ Sex } \\
\hline Male & 48,261 & 49.5 & 48,797 & 49.1 & 50,462 & 49.2 & 49,815 & 49.2 & 197,335 & 49.2 & NS & NS \\
\hline Female & 49,313 & 50.5 & 50,601 & 50.9 & 52,131 & 50.8 & 51,422 & 50.8 & 203,467 & 50.8 & & \\
\hline \multicolumn{13}{|c|}{ In-hospital death (in 30 days) } \\
\hline All patients & 16,178 & 16.6 & 16,234 & 16.3 & 16,700 & 16.3 & 16,249 & 16.1 & 65,361 & 16.3 & 0.0160 & 0.0009 \\
\hline \multicolumn{2}{|c|}{$\%$ age-sexe-adjusted } & 16.6 & & 16.2 & & 16.2 & & 15.9 & & & & \\
\hline Male & 7389 & 15.3 & 7430 & 15.2 & 7554 & 15.0 & 7285 & 14.6 & 29,658 & 15.0 & 0.0116 & 0.0006 \\
\hline$\%$ age-adjus & & 15.3 & & 15.1 & & 14.9 & & 14.6 & & & & \\
\hline$\leq 35$ & 86 & 7.1 & 77 & 6.4 & 83 & 6.2 & 63 & 5.6 & 309 & 6.3 & NS & 0.0765 \\
\hline $36-55$ & 547 & 8.1 & 561 & 8.3 & 577 & 8.2 & 550 & 7.8 & 2235 & 8.1 & NS & NS \\
\hline$>55$ & 6756 & 16.8 & 6792 & 16.6 & 6894 & 16.4 & 6672 & 16.0 & 27,114 & 16.5 & 0.0206 & 0.0010 \\
\hline Female & 8789 & 17.8 & 8804 & 17.4 & 9146 & 17.5 & 8964 & 17.4 & 35,703 & 17.6 & NS & NS \\
\hline$\%$ age-adjus & & 17.8 & & 17.4 & & 17.6 & & 17.4 & & & & \\
\hline$\leq 35$ & 62 & 4.9 & 49 & 3.8 & 51 & 4.1 & 46 & 3.9 & 208 & 4.2 & NS & NS \\
\hline $36-55$ & 416 & 8.9 & 407 & 8.7 & 374 & 7.6 & 386 & 8.3 & 1583 & 8.4 & NS & 0.0482 \\
\hline$>55$ & 8311 & 19.2 & 8348 & 18.7 & 8721 & 19.0 & 8532 & 18.7 & 33,912 & 18.9 & NS & NS \\
\hline
\end{tabular}

2011: Somers'd $\left.<10^{-3}\right)$. The trend was observed in both men $($ Somers'd $=0.0012)$ and women $\left(\right.$ Somers'd $\left.<10^{-3}\right)$. This trend was not found for ischemic strokes overall (Table 3) (Somers'd non-significant) even though significant differences were found in the distribution of patients by age group $(p=0.0235)$ in the different years. However, the structure by age and sex showed an increase in the proportion of men aged $36-55$ years $(12.4 \%$ in 2008 vs. $12.8 \%$ in 2011) and a fall in the proportion of those aged more than 55 years $(86.1 \%$ in 2008 vs. $85.7 \%$ in 2011 : Somers'd $=0.0462$ ). We found no statistically significant evolution in the structure according to age group in women.
In contrast (Table 2) the proportion of men aged 36-55 years who presented hemorrhagic stroke fell during the study period ( $19.6 \%$ in 2008 vs. $18.9 \%$ in 2011) whereas that in patients older than 55 years increased ( $74.4 \%$ in 2008 vs. $76.2 \%$ in 2011); the differences were significant (Somers'd $=0.0012$ ). The same significant trends were observed in women (Table 2) with a decrease in the proportion of women aged less than 36 years $(4.8 \%$ in 2008 vs. $4.0 \%$ in 2011 ) and in those aged $36-55$ years (17.2\% in 2008 vs. $15.4 \%$ in 2011) as well as an increase in those aged more than 55 years $(78.1 \%$ in 2008 vs. $80.7 \%$ in 2011). These differences were significant (Somers'd $<10^{-3}$ ). 
Table 2 Description of hemorrhagic strokes

\begin{tabular}{|c|c|c|c|c|c|c|c|c|c|c|c|c|}
\hline \multirow[t]{2}{*}{ Hemorrhagic strokes } & \multicolumn{2}{|l|}{2008} & \multicolumn{2}{|l|}{2009} & \multicolumn{2}{|l|}{2010} & \multicolumn{2}{|l|}{2011} & \multicolumn{2}{|l|}{ Total } & \multirow{2}{*}{$\begin{array}{l}x^{2} \\
p\end{array}$} & \multirow{2}{*}{$\begin{array}{l}\text { Somers'd } \\
\text { p }\end{array}$} \\
\hline & $\mathbf{n}$ & $\%$ & $\mathbf{n}$ & $\%$ & $\mathbf{n}$ & $\%$ & $\mathbf{n}$ & $\%$ & $\mathbf{n}$ & $\%$ & & \\
\hline All patients & 22,327 & & 22,618 & & 23,426 & & 23,056 & & 91,427 & & & \\
\hline \multicolumn{13}{|l|}{ Age } \\
\hline \multicolumn{13}{|l|}{ All patients } \\
\hline$\leq 35$ & 1205 & 5.4 & 1120 & 5.0 & 1169 & 5.0 & 1021 & 4.4 & 4515 & 4.9 & $<10^{-3}$ & $<10^{-3}$ \\
\hline $36-55$ & 4093 & 18.3 & 3946 & 17.5 & 4026 & 17.2 & 3935 & 17.1 & 16,000 & 17.5 & & \\
\hline$>55$ & 17,029 & 76.3 & 17,552 & 77.6 & 18,231 & 77.8 & 18,100 & 78.5 & 70,912 & 77.6 & & \\
\hline \multicolumn{13}{|l|}{ Male } \\
\hline$\leq 35$ & 663 & 6.0 & 599 & 5.4 & 676 & 5.9 & 551 & 4.9 & 2489 & 5.6 & 0.0007 & 0.0012 \\
\hline $36-55$ & 2152 & 19.6 & 2106 & 19.0 & 2077 & 18.2 & 2105 & 18.9 & 8440 & 18.9 & & \\
\hline$>55$ & 8192 & 74.4 & 8365 & 75.6 & 8673 & 75.9 & 8495 & 76.2 & 33,725 & 75.5 & & \\
\hline \multicolumn{13}{|l|}{ Female } \\
\hline$\leq 35$ & 542 & 4.8 & 521 & 4.5 & 493 & 4.1 & 470 & 4.0 & 2026 & 4.3 & $<10^{-3}$ & $<10^{-3}$ \\
\hline $36-55$ & 1941 & 17.2 & 1840 & 15.9 & 1949 & 16.2 & 1830 & 15.4 & 7560 & 16.2 & & \\
\hline$>55$ & 8837 & 78.1 & 9187 & 79.6 & 9558 & 79.7 & 9605 & 80.7 & 37,187 & 79.5 & & \\
\hline \multicolumn{13}{|l|}{ Sex } \\
\hline Male & 11,007 & 49.3 & 11,070 & 48.9 & 11,426 & 48.8 & 11,151 & 48.4 & 44,654 & 48.8 & NS & 0.0452 \\
\hline Female & 11,320 & 50.7 & 11,548 & 51.1 & 12,000 & 51.2 & 11,905 & 51.6 & 46,773 & 51.2 & & \\
\hline \multicolumn{13}{|c|}{ In-hospital death (in 30 days) } \\
\hline All patients & 7153 & 32.0 & 7367 & 32.6 & 7469 & 31.9 & 7438 & 32.3 & 29,427 & 32.2 & NS & NS \\
\hline$\%$ age-sexe-adjusted & & 32.0 & & 32.3 & & 31.6 & & 31.7 & & & & \\
\hline Male & 3450 & 31.3 & 3511 & 31.7 & 3657 & 32.0 & 3500 & 31.4 & 14,118 & 31.6 & NS & NS \\
\hline$\%$ age-adjusted & & 31.3 & & 31.5 & & 31.8 & & 31.0 & & & & \\
\hline$\leq 35$ & 72 & 10.9 & 58 & 9.7 & 68 & 10.1 & 58 & 10.5 & 256 & 10.3 & NS & NS \\
\hline $36-55$ & 379 & 17.6 & 407 & 19.3 & 422 & 20.3 & 399 & 19.0 & 1607 & 19.0 & NS & NS \\
\hline$>55$ & 2999 & 36.6 & 3046 & 36.4 & 3167 & 36.5 & 3043 & 35.8 & 12,255 & 36.3 & NS & NS \\
\hline Female & 3703 & 32.7 & 3856 & 33.4 & 3812 & 31.8 & 3938 & 33.1 & 15,309 & 32.7 & 0.0458 & NS \\
\hline$\%$ age-adjusted & & 32.7 & & 33.1 & & 31.4 & & 32.5 & & & & \\
\hline$\leq 35$ & 47 & 8.7 & 44 & 8.5 & 39 & 7.9 & 39 & 8.3 & 169 & 8.3 & NS & NS \\
\hline $36-55$ & 332 & 17.1 & 324 & 17.6 & 283 & 14.5 & 310 & 16.9 & 1249 & 16.5 & 0.0471 & NS \\
\hline$>55$ & 3324 & 37.6 & 3488 & 38.0 & 3490 & 36.5 & 3589 & 37.4 & 13,891 & 37.4 & NS & NS \\
\hline
\end{tabular}

Whatever the type of stroke and year, the mean age of women in the group aged more than 55 years was higher than that in men: (80.39 years [80.35-80.44] vs. 75.01 years $[74.97-75.06] \mathrm{p}<10^{-3}$ ) and this whatever the type of stroke: hemorrhagic : 78.24 years [78.14$78.35]$ vs. 70.03 years [73.93-74.14] $\left(\mathrm{p}<10^{-3}\right)$; ischemic: 80.96 years [80.91-81.00] vs. 75.27 years [75.21-75.32] $\left(\mathrm{p}<10^{-3}\right)$. Moreover, for this same age group, we found an increase in the mean age from 2008 to 2011 whatever the sex and type of stroke (Figs. 1, 2).

\section{In-hospital mortality}

For strokes overall (Table 1), we found a significant fall in the raw in-hospital mortality rate, which fell from $16.6 \%$ in 2008 to $16.1 \%$ in 2011, and in the standardized mortality rate (16.6 vs. $15.9 \%)$. The difference was significant
(Somers'd $=0.0009$ ). This fall in in-hospital mortality was especially due to the fall in the lethality of ischemic stroke (12.0\% in 2008 vs. $11.3 \%$ in 2011; Somers'd $<10^{-3}$ ) (Table 3), while in-hospital mortality in patients with hemorrhagic stroke (Table 2) remained stable and high ( $32.0 \%$ in 2008 vs. $32.3 \%$ in 2011; Somers'd NS).

For strokes overall (Table 1), the decrease in the raw and standardized mortality rates was only significant in men $($ Somers'd $=0.0006)$. However, the decrease in mortality rates following ischemic stroke over the period was statistically significant for both sexes (Table 3). In men, the raw mortality rate fell from $10.6 \%$ in 2008 to $9.8 \%$ in 2011 (Somers'd $<10^{-3}$ ) and in women it fell from $13.4 \%$ in 2008 to $12.7 \%$ in 2011 (Somers'd $=0.038$ ). This decrease concerned all age groups for men and the more than 55 years group for women. 
Table 3 Description of ischemic strokes

\begin{tabular}{|c|c|c|c|c|c|c|c|c|c|c|c|c|}
\hline \multirow[t]{2}{*}{ Ischemic strokes } & \multicolumn{2}{|l|}{2008} & \multicolumn{2}{|l|}{2009} & \multicolumn{2}{|l|}{2010} & \multicolumn{2}{|l|}{2011} & \multicolumn{2}{|l|}{ Total } & \multirow{2}{*}{$\begin{array}{l}x^{2} \\
p\end{array}$} & \multirow{2}{*}{$\begin{array}{l}\text { Somers'd } \\
p\end{array}$} \\
\hline & $\mathbf{n}$ & $\%$ & $\mathbf{n}$ & $\%$ & $\mathbf{n}$ & $\%$ & $\mathbf{n}$ & $\%$ & $\mathbf{n}$ & $\%$ & & \\
\hline All patients & 75,247 & & 76,780 & & 79,167 & & 78,181 & & 309,375 & & & \\
\hline \multicolumn{13}{|l|}{ Age } \\
\hline \multicolumn{13}{|l|}{ All patients } \\
\hline$\leq 35$ & 1271 & 1.7 & 1371 & 1.8 & 1417 & 1.8 & 1289 & 1.7 & 5348 & 1.7 & 0.0235 & NS \\
\hline $36-55$ & 7371 & 9.8 & 7449 & 9.7 & 7991 & 10.1 & 7771 & 9.9 & 30,582 & 9.9 & & \\
\hline$>55$ & 66,605 & 88.5 & 67,960 & 88.5 & 69,759 & 88.1 & 69,121 & 88.4 & 273,445 & 88.4 & & \\
\hline \multicolumn{13}{|l|}{ Male } \\
\hline$\leq 35$ & 557 & 1.5 & 603 & 1.6 & 656 & 1.7 & 576 & 1.5 & 2392 & 1.6 & 0.0347 & 0.0462 \\
\hline $36-55$ & 4634 & 12.4 & 4622 & 12.3 & 4992 & 12.8 & 4939 & 12.8 & 19,187 & 12.6 & & \\
\hline$>55$ & 32,063 & 86.1 & 32,502 & 86.2 & 33,388 & 85.5 & 33,149 & 85.7 & 131,102 & 85.9 & & \\
\hline \multicolumn{13}{|l|}{ Female } \\
\hline$\leq 35$ & 714 & 1.9 & 768 & 2.0 & 761 & 1.9 & 713 & 1.8 & 2956 & 1.9 & NS & NS \\
\hline $36-55$ & 2737 & 7.2 & 2827 & 7.2 & 2999 & 7.5 & 2832 & 7.2 & 11,395 & 7.3 & & \\
\hline$>55$ & 34,542 & 90.9 & 35,458 & 90.8 & 36,371 & 90.6 & 35,972 & 91.0 & 142,343 & 90.8 & & \\
\hline \multicolumn{13}{|l|}{ Sex } \\
\hline Male & 37,254 & 49.5 & 37,727 & 49.1 & 39,036 & 49.3 & 38,664 & 49.4 & 152,681 & 49.4 & NS & NS \\
\hline Female & 37,993 & 50.5 & 39,053 & 50.9 & 40,131 & 50.7 & 39,517 & 50.6 & 156,694 & 50.6 & & \\
\hline \multicolumn{13}{|c|}{ In-hospital death (in 30 days) } \\
\hline All patients & 9025 & 12.0 & 8867 & 11.6 & 9231 & 11.7 & 8811 & 11.3 & 35,934 & 11.6 & 0.0002 & $<10^{-3}$ \\
\hline \multicolumn{2}{|c|}{$\%$ age-sexe-adjusted } & 12.0 & & 11.5 & & 11.7 & & 11.3 & & & & \\
\hline Male & 3939 & 10.6 & 3919 & 10.4 & 3897 & 10.0 & 3785 & 9.8 & 15,540 & 10.2 & 0.0010 & $<10^{-3}$ \\
\hline \% age-adjusted & & 10.6 & & 10.4 & & 10.0 & & 9.8 & & & & \\
\hline$\leq 35$ & 14 & 2.5 & 19 & 3.2 & 15 & 2.3 & 5 & 0.9 & 53 & 2.2 & 0.0574 & 0.0088 \\
\hline $36-55$ & 168 & 3.6 & 154 & 3.3 & 155 & 3.1 & 151 & 3.1 & 628 & 3.3 & NS & 0.0493 \\
\hline$>55$ & 3757 & 11.7 & 3746 & 11.5 & 3727 & 11.2 & 3629 & 11.0 & 14,859 & 11.3 & 0.0082 & 0.0003 \\
\hline Female & 5086 & 13.4 & 4948 & 12.7 & 5334 & 13.3 & 5026 & 12.7 & 20,394 & 13.0 & 0.0023 & 0.0380 \\
\hline$\%$ age-adjusted & & 13.4 & & 12.7 & & 13.3 & & 12.7 & & & & \\
\hline$\leq 35$ & 15 & 2.1 & 5 & 0.7 & 12 & 1.6 & 7 & 1.0 & 39 & 1.3 & NS & NS \\
\hline $36-55$ & 84 & 3.1 & 83 & 2.9 & 91 & 3.0 & 76 & 2.7 & 334 & 2.9 & NS & NS \\
\hline$>55$ & 4987 & 14.4 & 4860 & 13.7 & 5231 & 14.4 & 4943 & 13.7 & 20,021 & 14.1 & 0.0031 & 0.0466 \\
\hline
\end{tabular}

We found no significant variation in mortality rates according to age group and sex for hemorrhagic strokes (Table 2).

Table 4 shows that, in our population, the risk of dying in hospital in the 30 days following a stroke whatever the type was lower in men than in women (relative risk: male/ female (RR): 0.86 [95 \% CI 0.84-0.87]). Nonetheless, the $R R$ was different depending on the age group and type of stroke. For both types (hemorrhagic and ischemic), women older than 55 years presented a higher risk of death than men of the same age group (RR: 0.97 [95\% CI 0.95-0.98] for hemorrhagic and RR: 0.78 [95 \% CI 0.77-0.80] for ischemic). However, for patients younger than 36 years, the risk was lower in women for both types of stroke (RR: 1.23 [95 \% CI 1.02-1.48] for hemorrhagic and RR: 1.68 [95 \% CI 1.11-2.53] for ischemic), and for hemorrhagic stroke in women aged 36-55 years (RR: 1.15 [95 \% CI 1.08-1.23]).

\section{Spatial analysis of in-hospital mortality}

The overall decrease in in-hospital mortality over the 4 years of the study masks stark spatial differences in France (c.f. Fig. 3). The map of the standardized rates illustrates a concentration of high stroke-related mortality along a north-east/south-west diagonal, as well as high rates in Brittany departments. The highest rates are seen in central departments and in Haute-Corse, in north of Corsica. In contrast, the departments of Ile-de-France, Rhône, Isere and Haute-Savoie have the lowest rates.

At the level of geographic codes (c.f. Fig. 4), the map shows clusters with high in-hospital mortality, notably in central Brittany and along a geographical diagonal of high 


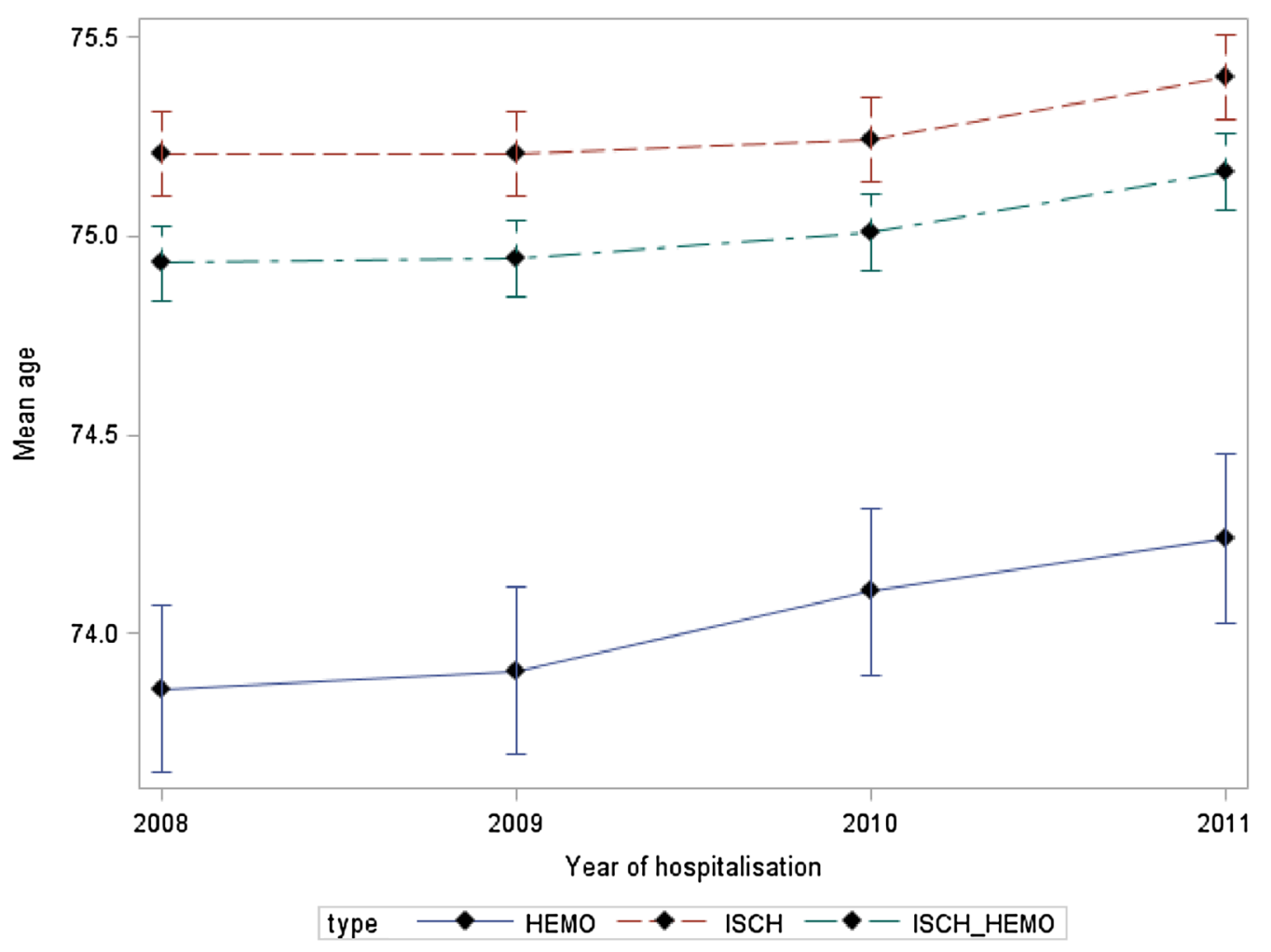

Fig. 1 Mean age, male over 55 years old

mortality through the country, following a north-east/ south-west axis. Areas bordering the Rhône and Loire valleys, Alsace and the north-east of the Rhone-Alps region, however, appear to be better protected. In Corsica, areas around the town of Calvi, in the north-west of the island are particularly affected by high mortality.

Tables 5 and 6 present the results of the ascending hierarchical classification at the level of PMSI geographic codes and the characteristics of each cluster. Cluster 1 represents urban areas, near large towns or areas that benefit from the attraction of nearby large towns. Stroke-related mortality is low in these areas; the population is younger than elsewhere, as shown by the lower proportion of over $60 \mathrm{~s}$ and pensioners, but the occupational profile was more precarious, with a high proportion of unemployed, intermediate workers and manual workers compared with the low proportion of managers or professional occupations.

Cluster 2, which also represents urban and peri-urban France, has low stroke-related mortality but unlike cluster 1 has a high socio-economic status with a higher proportion of managers and professional occupations and a lower proportion of manual workers and unemployed than in other clusters. This cluster mainly includes periurban areas situated in the affluent suburbs of large agglomerations: west of Ile-de-France, Lille, Nancy,
Strasbourg, Lyon, Montpellier, Toulouse, Bordeaux, Nantes, Rennes.

Cluster 3 includes dynamic rural areas of the west and east of France. Stroke-related mortality in these areas is relatively low and the population is relatively younger than in other clusters.

The areas in cluster 4 are mostly situated along the coast in the south and south-east of the country in Provence, in the Alps, and Corsica, and are characterized by an aging population, high levels of unemployment and high stroke-related in-hospital mortality.

The spatial distribution of high stroke-related in-hospital mortality seems to follow the north-east/south-west axis (cf. Figs. 3, 4), as shown by the results of the AHC (cf. Fig. 5). Areas with low in-hospital mortality are also those with favorable socio-professional and demographic structures. Areas with high mortality (Fig. 4) corresponded visually with areas in cluster 5 , which have low-income occupations, pensioners or pre-retirees and an older population.

For the country as a whole, the spatial distribution of socio-economic and healthcare indicators seems to favor areas around large towns or departmental prefectures. Young people and tertiary-sector professions are concentrated in these main towns (cluster 1), which have a denser healthcare structure and show low stroke-related 


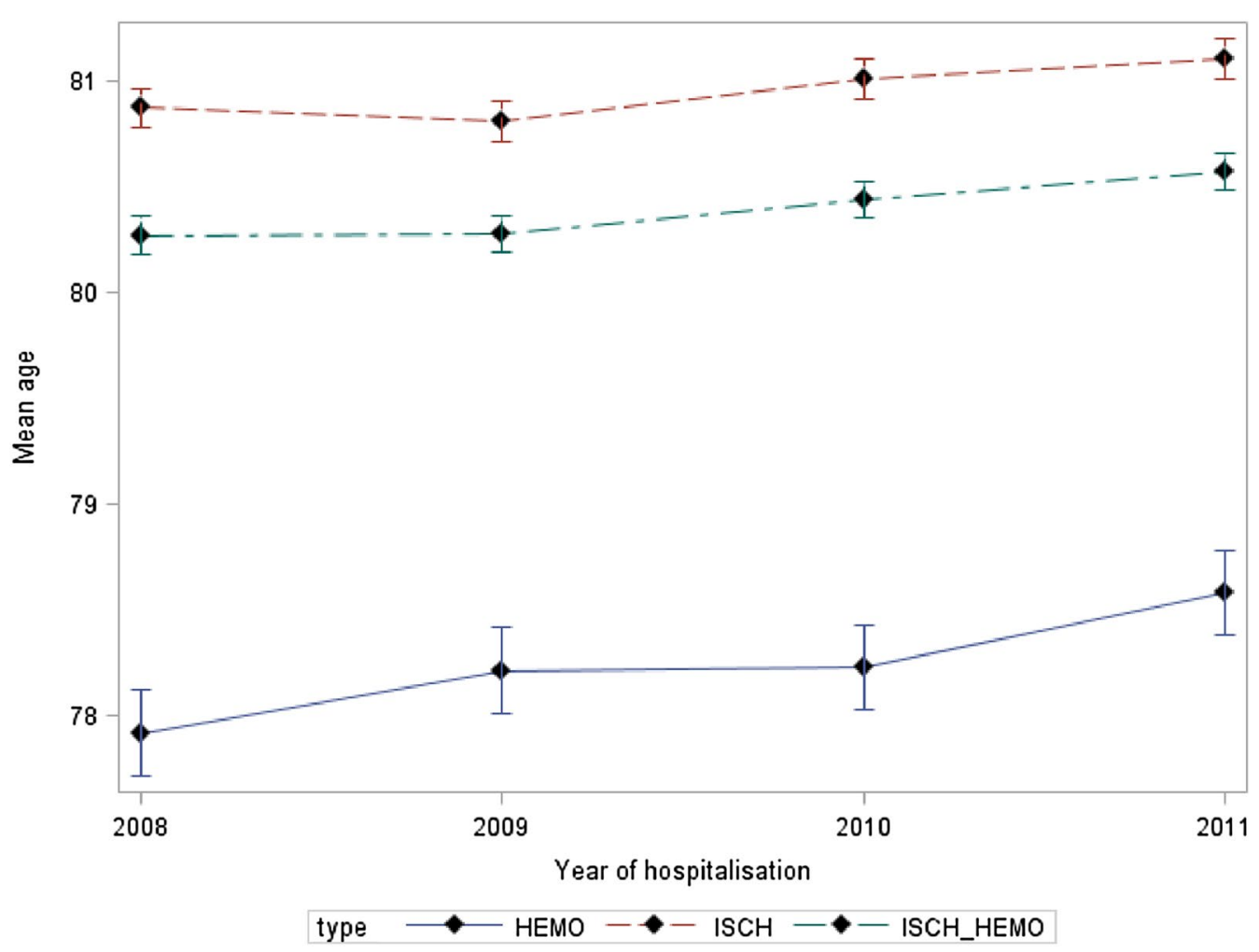

Fig. 2 Mean age, female over 55 years old

Table 4 Relative risk of in-hospital mortality, comparison between males and females

\begin{tabular}{|c|c|c|c|c|c|c|c|c|c|}
\hline & \multicolumn{9}{|c|}{ Relative risk (RR:male:female) } \\
\hline & \multicolumn{3}{|c|}{ Hemorrhagic + ischemic strokes } & \multicolumn{3}{|c|}{ Hemorrhagic strokes } & \multicolumn{3}{|c|}{ Ischemic strokes } \\
\hline & $\mathbf{R R}$ & $95 \%$ & & $\mathbf{R R}$ & $95 \%$ & & $\mathbf{R R}$ & $95 \%$ & \\
\hline \multicolumn{10}{|l|}{ Age } \\
\hline$\leq 35$ & 1.51 & 1.28 & 1.80 & 1.23 & 1.02 & 1.48 & 1.68 & 1.11 & 2.53 \\
\hline $36-55$ & 0.97 & 0.91 & 1.03 & 1.15 & 1.08 & 1.23 & 1.12 & 0.98 & 1.27 \\
\hline$>55$ & 0.87 & 0.86 & 0.88 & 0.97 & 0.95 & 0.99 & 0.81 & 0.79 & 0.82 \\
\hline All & 0.86 & 0.84 & 0.87 & 0.97 & 0.95 & 0.98 & 0.78 & 0.77 & 0.80 \\
\hline
\end{tabular}

$\mathrm{Cl}$ confidence interval

mortality. The affluent suburbs of these main towns (cluster 2) are organized in a concentric pattern around these urban centers. Further away, rural areas associated with these urban centers (cluster 3) also have low mortality, but also include large underprivileged areas with aging populations (clusters 4 and 5).

\section{Discussion}

The list of diagnostic codes used to select patients corresponded to those used in other studies on stroke mortality, in France [8], and internationally [9].
Different sensitivity and validation analyses have shown the robustness of the methodology [10, 11]. However, following a validation study of PMSI data [8], our selection criteria differed slightly from those of Peretti et al. Our selection of hemorrhagic stroke was based on codes I60 and I61 and notably on code I62.9. We did not use all I62 codes, given their lower sensitivity according to a validation study of PMSI data [8]. Moreover, patients suffering from TIA were not included in our study given the heterogeneous nature of coding practices [12]. 


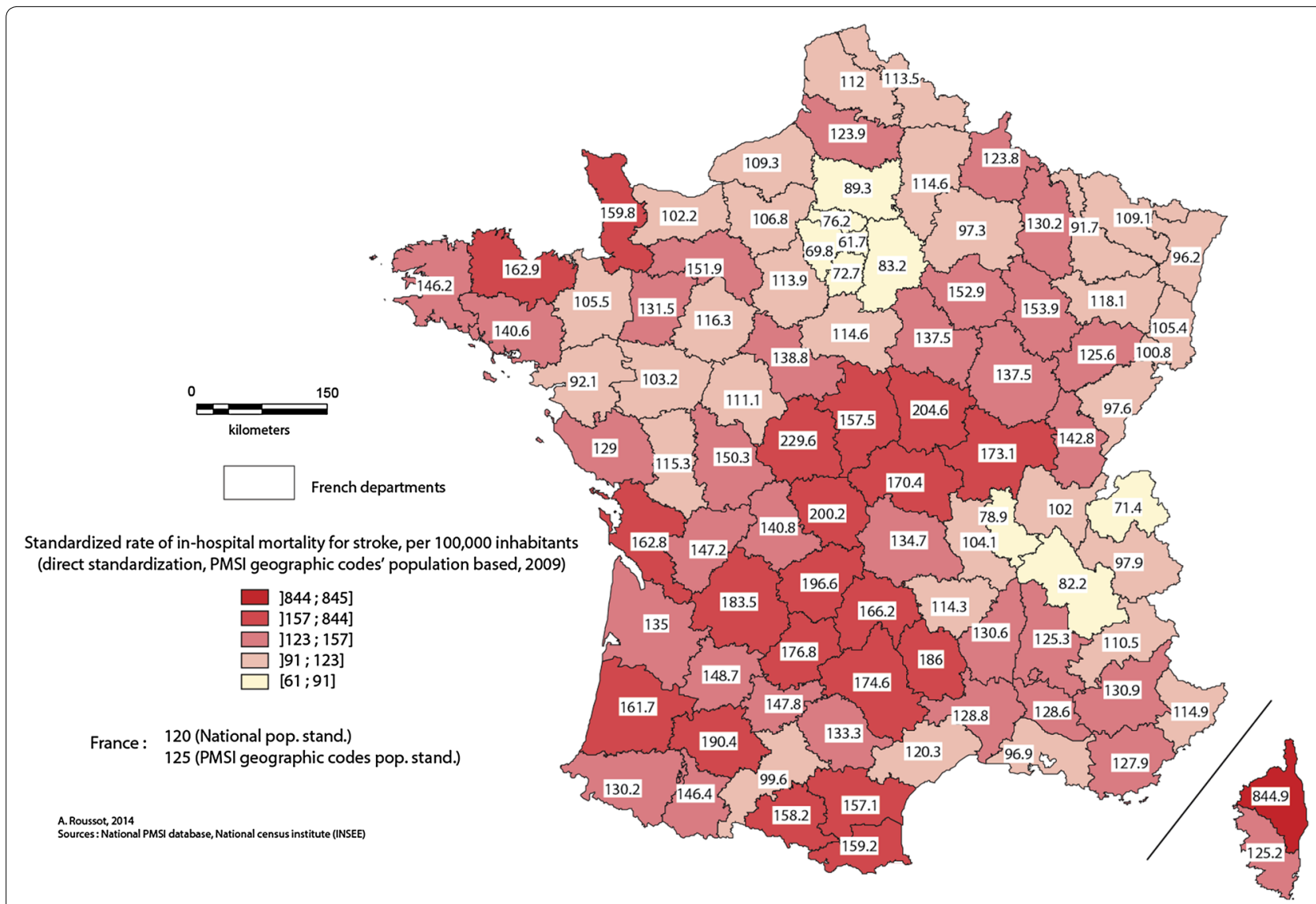

Fig. 3 Standardized rate of in-hospital mortality at the departmental level, 2008-2011

According to the national PMSI databases, overall, the number of patients hospitalized for stroke increased in France from 2008 to 2011, despite a fall between 2010 and 2011. This increase was not homogeneous and depended on the age group. The greatest increases affected patients older than 55 years, which is in line with demographic change: in France according to the INSEE, the number of persons aged over 55 years increased by $2.5 \%$ between 2008 and 2011.

The majority of patients hospitalized following stroke were women, which is in keeping with the results of an earlier study conducted in France [13]. Moreover, our study shows that the increase in the proportion of patients older than 55 years affects women more than men in this his age group. This result agrees with the results of recent study [14], which show that with the increased life expectancy in developed countries, women contribute more than men to the increased prevalence and incidence of stroke in the oldest age group. This increased life expectancy without stroke was shown in an earlier study, which reported a mean increase of 5 years in men and of 8 years in women of stroke in Dijon,
France between 1987 and 2008 [15]. This trend over the same period was also found in Sweden [16] and in NewZealand [17].

The increase concerning the 36-55 years age group for ischemic stroke, notably in men, is in keeping with recent data, whether from different population registries or from medico-administrative data [7], and with trends observed worldwide $[1,18,19]$. This increase is certainly multifactorial and raises the problem of uncontrolled or increasing risk factors in this population. Such factors include smoking, diabetes, hypercholesterolemia, obesity, or cannabis consumption [18, 20-25]. These results indicate that primary vascular prevention is necessary throughout life and should start in childhood.

At the same time, the characteristics of the hospital stay have changed. First, the mean length of hospital stay decreased and secondly, there was a clear fall in in-hospital mortality. According to a validation study conducted by the Technique de l'Information Hospitaliere (ATIH) and INSEE, the quality of recording in-hospital mortality in the PMSI database has improved. We thus focused a part of our analysis on this indicator of performance 


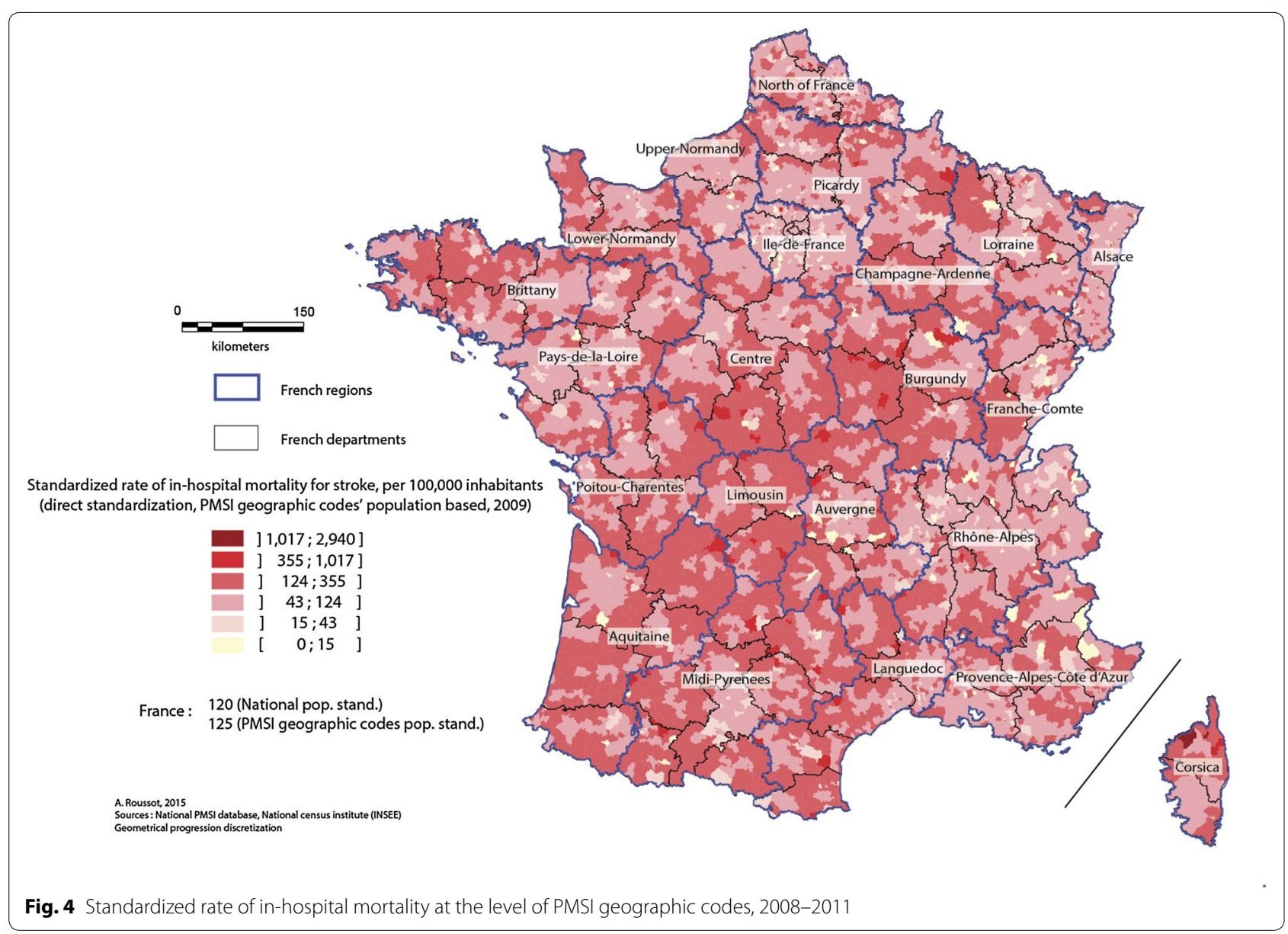

Table 5 Results of the HAC

\begin{tabular}{|c|c|c|c|c|c|c|}
\hline Variable & $\begin{array}{l}\text { Overall } \\
\text { mean }\end{array}$ & $\begin{array}{l}\text { Cluster } 1 \\
\text { Prob (test) }>0\end{array}$ & $\begin{array}{l}\text { Cluster } 2 \\
\text { Prob (test) }>0\end{array}$ & $\begin{array}{l}\text { Cluster } 3 \\
\text { Prob (test) }>0\end{array}$ & $\begin{array}{l}\text { Cluster } 4 \\
\text { Prob (test) }>0\end{array}$ & $\begin{array}{l}\text { Cluster } 5 \\
\text { Prob (test) }>0\end{array}$ \\
\hline Farmers (\%) & 3.30 & $<0.0001$ & $<0.0001$ & $<0.0001$ & $<0.0001$ & $<0.0001$ \\
\hline Craftsmen-storekeepers-entrepreneurs (\%) & 6.91 & & & & & \\
\hline Managers or professional occupations (\%) & 11.20 & & & & 0.2305 & \\
\hline Intermediate professions—-technicians (\%) & 22.99 & & & & 0.0244 & \\
\hline Employees (\%) & 28.48 & & & & & \\
\hline Skilled workers (\%) & 26.15 & & & & $<0.0001$ & \\
\hline $0-20$ years old $(\%)$ & 24.20 & & & & & \\
\hline 20-60 years old (\%) & 51.48 & & & & & \\
\hline $60+(\%)$ & 24.80 & & & & & \\
\hline Unemployed persons (\%) & 10.93 & & & & & \\
\hline 15-64 years old retired or pre-retired persons (\%) & 14.84 & & & & & \\
\hline $\begin{array}{l}\text { Standardized rate of in-hospital mortality } \\
\text { for stroke }\end{array}$ & 122.58 & & & & & \\
\hline
\end{tabular}

of the healthcare system, especially since this type of analysis is becoming more widespread with the growing use of medico-administrative data [26-28]. The reduced in-hospital mortality observed for hospital stays overall corresponds to observations of a French study, which reported that the proportion of intra-hospital deaths 
Table 6 Characteristics of clusters from the HAC

\begin{tabular}{|c|c|c|c|c|c|}
\hline Cluster & 1 & 2 & 3 & 4 & 5 \\
\hline \multicolumn{6}{|l|}{ Socio-professional category (mean in each cluster) } \\
\hline Farmers (\%) & 1.17 & 0.57 & 4.06 & 1.96 & 11.02 \\
\hline Craftsmen storekeepers entrepreneurs (\%) & 5.49 & 6.26 & 6.23 & 9.68 & 9.39 \\
\hline Managers or professional occupations (\%) & 9.96 & 24.65 & 8.54 & NS & 6.56 \\
\hline Intermediate professions —-technicians (\%) & 23.41 & 29.15 & 21.95 & 23.32 & 17.77 \\
\hline Employees (\%) & 30.96 & 24.24 & 26.86 & 31.53 & 26.97 \\
\hline Skilled workers (\%) & 27.69 & 14.38 & 31.61 & 21.32 & 27.29 \\
\hline \multicolumn{6}{|l|}{ Demographic structure (mean in each cluster) } \\
\hline $0-20$ years old $(\%)$ & 25.47 & 26.24 & 25.77 & 20.69 & 19.45 \\
\hline 20-60 years old $(\%)$ & 53.05 & 53.91 & 52.25 & 48.42 & 46.95 \\
\hline $60+(\%)$ & 21.90 & 20.07 & 22.53 & 31.36 & 34.30 \\
\hline \multicolumn{6}{|l|}{ Sanitary variable (mean in each cluster) } \\
\hline Unemployed persons (\%) & 13.15 & 7.80 & 9.30 & 12.94 & 10.12 \\
\hline 15-64 years old retired or pre-retired persons (\%) & 13.50 & 11.33 & 13.77 & 18.63 & 19.75 \\
\hline Standardized rate of in-hospital mortality for stroke (per 100,000 inhabitants) & 105.13 & 76.47 & 114.07 & 155.41 & 193.41 \\
\hline
\end{tabular}

during the first hospital stay for stroke had fallen significantly by 0.5 percentage points between 2007 and 2009 [7]. These observations could be related to the better reactivity of hospital emergency departments and the earlier arrival of patients. On this subject, another study pointed out the efficacy of fibrinolysis in patients with ischemic stroke in a context of reinforced on-call duty in specialized neurology units, stroke units $[29,30]$.

Our results also indicate that raw and standardized mortality rates were significantly higher in women than in men, which was also shown in another study conducted in France [13]. However, this excess mortality following stroke in women was not found at the level of all developed countries, where mortality rates in men are higher than those in women [31]. In our study, however, this excess mortality in women was only found for women aged 56 years and over. Yet, for this age group, the mean age of women was 80 and 5 years older than that of men. As mortality increases with age, this difference in mean ages may explain the excess mortality. In contrast, there was excess mortality in men younger than 56 years for hemorrhagic stroke, and in those younger than 36 years for ischemic stroke. The RR observed in our study for these age groups were of the same order of magnitude as those observed in the United States in young adults [32].

Our spatial study is the first to be conducted at the level of PMSI geographic codes in France. The results using this approach were more accurate than those obtained at the department level. Indeed, earlier studies have already investigated the geographic distribution of stroke prevalence and mortality at the global scale $[1,33]$. These studies showed an increase in stroke prevalence associated with a fall in mortality in high-income developed countries, like France. However, we do not have such a smallscale spatial analysis of stroke-related mortality in France. Our work therefore showed the interest of associating medical data with socio-economic data from the national census, which is available at the post-code level. Concerning in-hospital mortality, this association could be used for other diseases and in other countries, depending on the availability of databases and the scale of analysis they allow.

Two major results came out of this study. The map of standardized mortality rates allowed us first of all to illustrate the territorial disparities at the national level, and notably by identifying areas of high mortality from the north-east to the south-west of the country, along the "low population density diagonal". Areas along this diagonal are characterized by aging communities, but the excess mortality cannot be explained by age differences alone as age-standardized mortality was also higher than elsewhere. This zone, which we call the "excess mortality diagonal" had already been pointed out by French geographers, notably in terms of premature death in the population at large [34]. Another hypothesis to explain the high mortality rate could be that these territories are often far from emergency care facilities; this aspect has already been mentioned in several studies [35, 36]. Moreover, if we consider that patients hospitalized for stroke are hospitalized as close as possible to their homes, given that emergency care facilities are supposed to be nearby, these results indicate the location of "protective" and "accidentogenic" zones on a very small scale. Local observations could provide a diagnostic tool for decisionmakers to assess the quality of prevention, to evaluate the 


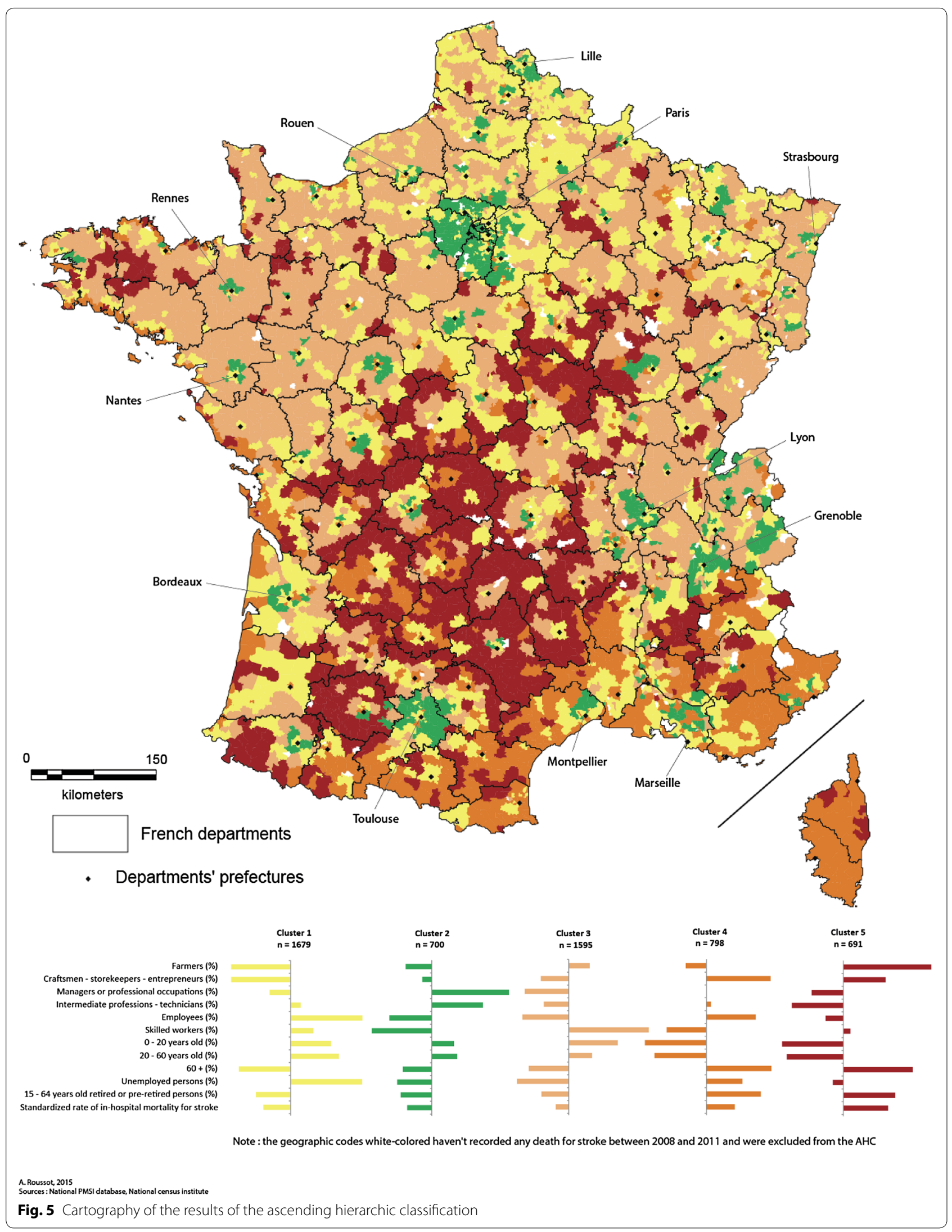


efficacy of public healthcare messages and the burden of risk factors in certain areas [37, 38].

The isolation of certain rural areas raises the question of the development of telemedicine in the most serious cases of stroke, which require fibrinolysis. Concerning the management of ischemic strokes, telemedicine makes it possible to link small isolated rural hospitals with major hospitals where neurologists are available round the clock. Teleconsultations allow duty neurologists to help doctors in smaller hospitals to perform thrombolysis when necessary. The deployment of such systems enables the earlier management of stroke victims close to where the stroke occurred and avoids transfers to distant hospitals or stroke units. Telemedicine programs are being deployed in several French regions, notably in Burgundy, a region marked by the isolated rural areas in the centre and recent hospital restructuration. A previous study in the region brought to light the link between the isolation of populations from the healthcare system and poorer results in perinatal care [39]. However, an overall evaluation of these telemedicine programs using national claims data is difficult to achieve, as they are often too recent and because the coding of telemedicine procedures is not consistent. Studies to identify patients who have benefitted from telemedicine are nonetheless under way, but researchers need to go back to patients' medical records at the various establishments [40, 41]. Moreover, several tests were conducted with different variables in the AHC for this study, but we chose to represent the analysis that generated the greatest inertia (69.2\%). The results obtained with variables relative to access to the healthcare system were less satisfactory: these variables were time to reach a stroke unit or a hospital emergency unit, in minutes for each geographic code.

Standardization of mortality rates on a small scale, according to the geographic code of the patient's place of residence, revealed local clusters of high mortality, notably in Brittany. This analysis of local situations, which is more detailed than analyses at the departmental level, highlighted territorial disparities, but cannot replace the results of even smaller scale analyses, at the level INSEE codes for communes, for example. We intend to continue our work using SNIIRAM data, which will allow us to break away from the use of aggregated population data to calculate incidences or comparative indices of mortality. An earlier study underlined the interest of analyzing stroke incidence at the IRIS level (Ilots regroupés pour l'information statistique) using registry data [42, 43]. The analysis established a link between an underprivileged environment and the greater incidence of stroke. Mortality rates were also higher among lower wage earners.

The 5 clusters from the classification divide the territory according to the weight of each variable selected by the AHC. Classification was preferred for this study because it can be used to establish a solid typology that maximizes the resemblance between observations (PMSI geographic codes) within the same cluster. Concerning the ageing population in certain areas, the model presented includes the demographic structure of the geographic codes of the place of residence, as well as the smoothed rate of in-hospital mortality. These variables are treated independently in the classification, which allowed us to contextualize certain high mortality rates. Despite the adjustment for age, areas marked by high mortality were also those with the oldest population. The classification showed that the demographic structure was not the only factor of the socio-territorial organization to affect mortality. Indeed, apart from the age of the population, disparities in mortality also followed the territorial distribution of socio-professional categories. It thus appears that social difficulties and problems linked to the ageing of the population are associated with higher stroke-related mortality than is the case in certain rural or peri-urban areas. The interest of the AHC is justified by the difficulty of linking the healthcare results of a large population with their socio-economic conditions as there are as yet no indicators of this type at the individual level in French medico-administrative databases. Clustering techniques and the geographic approach provided an idea of aggregated healthcare results at a territorial level and illustrated the interplay between the socio-economic environment and healthcare issues, such as, among others, mortality in England and Wales [2] or access to the healthcare system in France [44, 45].

\section{Conclusions}

Since the implementation of the National Stroke Plan, most studies have reported better management of patients in France, where the incidence of stroke was amongst the lowest in the world, thanks to the geographic, social and healthcare conditions in the country [46]. In this respect, in-hospital mortality in patients with ischemic stroke has markedly improved thanks to the reinforcement of the stroke units network and the generalization of fibrinolysis and in spite of the increase in the number of people hospitalized. This study makes it easier to understand that the fall in in-hospital mortality was not uniform throughout the country and was accompanied by considerable territorial diversity. We showed that the spatial distribution of healthcare indicator such like in-hospital mortality follows the distribution of demographic and social inequalities. The clustering method showed that areas characterized by unfavorable socio-economic indicators are also affected by high inhospital mortality. We also know that areas on the "excess mortality diagonal" are often far away from the nearest 
emergency care facilities. Our study was conducted in the context of a wider program of the territorial organization of healthcare policies to counter the isolation and aging of rural areas. The development of telemedicine programs, another priority axis of the National Stroke Plan, should accelerate the remote management of patients and guarantee better integrated healthcare in these isolated communities.

\section{Ethics approval and consent to participate}

This study was approved by the National Committee for data protection (Commission Nationale de l'Informatique et des Libertés, registration number 1576793) and was conducted in accordance with French legislation. The PMSI database was transmitted by the national agency for the management of hospitalization data (ATIH number 2015-111111-47-33).

\section{Consent for publication}

\section{Written consent was not needed for this study.}

\begin{abstract}
Abbreviations
PMSI-MCO: Programme de médicalisation des systèmes d'information en Médecine, Chirurgie et Obstétrique; SNIIR-AM: Système national inter-régime de l'assurance maladie; ICD 10: International Classification of Diseases, 10th revision; PD: principal diagnosis; DRG: Diagnosis Related Group; INSEE: Institut National de la Statistique et des Etudes Economiques; ATIH: Agence Technique de I'Information Hospitalière; PCA: principal components analysis; AHC: ascending hierarchical classification; GIS: geographic information system; LOS: length of hospital stay.
\end{abstract}

\section{Authors' contributions \\ AR: conceptualized and designed the study, conducted the statistical and cartographical analysis, wrote the article. JC: extracted the data, supported the statistical analysis, read back and corrected the article. MG: contributed substantially to the conception of the study and the interpretation of the results. MG: participated in the interpretation of the results and supported the discussion part. YB: participated in the interpretation of the results and sup- ported the discussion part. CQ: designed the study, oversaw the data analysis and interpretation and critically reviewed and revised the manuscript drafts. All authors read and approved the final manuscript.}

\section{Authors' information}

Catherine Quantin is Professor and head of department of Biostatistics and Medical Informatics in Dijon Teaching Hospital and member of the INSERM U866 team. She works on medical databases in the field of public health and developed new methods in anonymous identification and linkage. She is active in several colleges of medical informatics and epidemiology in France and in the International Society for Clinical Biostatistics (ISCB). She has organized twelve national or international conferences or workshop (IMIA). She is the Editor-in-Chief of the Journal d'Economie et de Gestion Médicales and the lead author/co-author of almost 160 international publications.

\footnotetext{
Author details

1 Service de Biostatistique et d'Informatique Médicale (DIM), CHRU Dijon, Dijon 21000 , France. ${ }^{2}$ Université de Bourgogne, Dijon 21000 , France. ${ }^{3}$ Laboratoire d'Economie de Dijon, Université de Bourgogne, UMR 6307 CNRS, INSERM U1200, Dijon, France. ${ }^{4}$ Registre des AVC dijonnais, EA4184, CHRU, Univ de Bourgogne, Dijon, France. ${ }^{5}$ INSERM, CIC 1432, Dijon, France. ${ }^{6}$ Clinical Epidemiology/Clinical Trials Unit, Clinical Investigation Center, Dijon University Hospital, Dijon, France. ${ }^{7}$ Biostatistics, Biomathematics, Pharmacoepidemiology and Infectious Diseases (B2PHI), Univ. Bourgogne Franche-Comté, Inserm UMR 1181, Dijon 21000, France.
}

\section{Acknowledgements}

This work was supported by the Conseil Regional de Bourgogne. The authors thank M. Philip Bastable for reviewing the English version.

\section{Competing interests}

The authors declare that they have no competing interests.

Received: 12 May 2015 Accepted: 7 December 2015

Published online: 11 January 2016

\section{References}

1. Feigin VL, Forouzanfar MH, Krishnamurthi R, Mensah GA, Connor M, Bennett DA, et al. Global and regional burden of stroke during 1990-2010: findings from the Global Burden of Disease Study 2010. Lancet. 2014;383(9913):245-54.

2. Wang H, Liddell CA, Coates MM, Mooney MD, Levitz CE, Schumacher AE, et al. Global, regional, and national levels of neonatal, infant, and under-5 mortality during 1990-2013: a systematic analysis for the Global Burden of Disease Study 2013. Lancet. 2014;384(9947):957-79.

3. Plan d'actions national "accidents vasculaires cérébraux 2010-2014", (2010).

4. La prévention et la prise en charge des accidents vasculaires cérébraux en France.: Ministère de la santé et des sportsjuin 2009.

5. Goldberg M, Coeuret-Pellicer M, Ribet C, Zins M. Epidemiological studies based on medical and administrative databases: a potential strength in France. Med Sci (Paris). 2012;28(4):430-4.

6. Chevreul K, Durand-Zaleski I, Gouepo A, Fery-Lemonnier E, Hommel M, Woimant F. Cost of stroke in France. Eur J Neurol. 2013;20(7):1094-100.

7. de Peretti C, Nicolau J, Tuppin P, Schnitzler A, Woimant F. Acute and post-acute hospitalizations for stroke in France: recent improvements (2007-2009). Presse Med. 2012;41(5):491-503.

8. Aboa-Eboule C, Mengue D, Benzenine E, Hommel M, Giroud M, Bejot Y, et al. How accurate is the reporting of stroke in hospital discharge data? A pilot validation study using a population-based stroke registry as control. J Neurol. 2013;260(2):605-13.

9. Kokotailo RA, Hill MD. Coding of stroke and stroke risk factors using international classification of diseases, revisions 9 and 10. Stroke. 2005;36(8):1776-81.

10. Wright FL, Green J, Canoy D, Cairns BJ, Balkwill A, Beral V. Vascular disease in women: comparison of diagnoses in hospital episode statistics and general practice records in England. BMC Med Res Methodol. 2012;12:161.

11. Johnsen SP, Overvad K, Sorensen HT, Tjonneland A, Husted SE. Predictive value of stroke and transient ischemic attack discharge diagnoses in The Danish National Registry of Patients. J Clin Epidemiol. 2002;55(6):602-7.

12. Etude des algorithmes de définition des pathologies dans le système national d'information inter-régimes de l'assurance maladie (SNIIRAM). Rapport CnamTS en cours de publication.

13. De Peretti C. Les risques de décès un an après un accident vasculaire cérébral. Etudes et Résultats. Rapport DREES no. 0939.2015.

14. Feigin VL, Krishnamurthi RV, Parmar P, Norrving B, Mensah GA, Bennett DA, et al. Update on the Global Burden of Ischemic and Hemorrhagic Stroke in 1990-2013: The GBD 2013 Study. Neuroepidemiology. 2015;45(3):161-76.

15. Bejot Y, Gentil A, Biotti D, Rouaud O, Fromont A, Couvreur G, et al. [What has changed for stroke at the beginning of the 21st century]. Rev Neurol (Paris). [Review]. 2009;165(8-9):617-25.

16. Terent A. Trends in stroke incidence and 10-year survival in Soderhamn, Sweden, 1975-2001. Stroke. 2003;34(6):1353-8.

17. Anderson CS, Carter KN, Hackett ML, Feigin V, Barber PA, Broad JB, et al. Trends in stroke incidence in Auckland, New Zealand, during 1981-2003. Stroke. 2005;36(10):2087-93.

18. Bejot Y, Daubail B, Jacquin A, Durier J, Osseby GV, Rouaud O, et al. Trends in the incidence of ischaemic stroke in young adults between 1985 and 2011: the Dijon Stroke Registry. J Neurol Neurosurg Psychiatry. 2014;85(5):509-13.

19. Kissela BM, Khoury JC, Alwell K, Moomaw CJ, Woo D, Adeoye O, et al. Age at stroke: temporal trends in stroke incidence in a large, biracial population. Neurology. 2012;79(17):1781-7. 
20. de los Rios F, Kleindorfer DO, Khoury J, Broderick JP, Moomaw CJ, Adeoye $\mathrm{O}$, et al. Trends in substance abuse preceding stroke among young adults: a population-based study. Stroke. 2012; 43(12):3179-83.

21. Dube SR, McClave A, James C, et al. Vital signs: current cigarette smoking among adults aged $\geq 18$ years-United States, 2009. Morbidity Mortality Weekly Report (MMWR). 2010; 59:1135-40.

22. Kanny D, Liu Y, Brewer RD. Vital Signs: Binge drinking among high school students and adults-United States, 2009. Morbidity and Mortality Weekly Report (MMWR). 2010;59(39):1274-9.

23. Kusnik-Joinville O, Weill A, Salanave B, Ricordeau P, Allemand H. Prevalence and treatment of diabetes in France: trends between 2000 and 2005. Diabetes Metab. 2008;34(3):266-72.

24. Marques-Vidal P, Ruidavets JB, Cambou JP, Ferrieres J. Changes and determinants in cigarette smoking prevalence in southwestern France, 1985-1997. Eur J Public Health. 2003;13(2):168-70.

25. Pigeyre M, Dauchet L, Simon C, Bongard V, Bingham A, Arveiler D, et al Effects of occupational and educational changes on obesity trends in France: the results of the MONICA-France survey 1986-2006. Prev Med. 2011;52(5):305-9.

26. Chang KC, Lee HC, Huang YC, Hung JW, Chiu HE, Chen JJ, et al. Costeffectiveness analysis of stroke management under a universal health insurance system. J Neurol Sci. 2012;323(1-2):205-15.

27. Lee HC, Chang KC, Huang YC, Hung JW, Chiu HH, Chen JJ, et al. Readmission, mortality, and first-year medical costs after stroke. J Chin Med Assoc. 2013;76(12):703-14

28. Lee J, Morishima T, Kunisawa S, Sasaki N, Otsubo T, Ikai H, et al. Derivation and validation of in-hospital mortality prediction models in ischaemic stroke patients using administrative data. Cerebrovasc Dis. 2013;35(1):73-80

29. Raffe F, Jacquin A, Milleret O, Durier J, Sauze D, Peyron C, et al. Evaluation of the possible impact of a care network for stroke and transient ischemic attack on rates of recurrence. Eur Neurol. 2011;65(4):239-44.

30. Nimptsch U, Mansky T. Stroke unit care and trends of in-hospital mortality for stroke in Germany 2005-2010. Int J Stroke. 2014;9(3):260-5.

31. Krishnamurthi RV, Moran AE, Feigin VL, Barker-Collo S, Norrving B, Mensah GA, et al. Stroke prevalence, mortality and disability-adjusted life years in adults aged 20-64 years in 1990-2013: data from the global burden of disease 2013 study. Neuroepidemiology. 2015;45(3):190-202.

32. Poisson SN, Glidden D, Johnston SC, Fullerton HJ. Deaths from stroke in US young adults, 1989-2009. Neurology. 2014;83(23):2110-5.
33. Feigin VL, Mensah GA, Norrving B, Murray CJ, Roth GA. Atlas of the Global Burden of Stroke (1990-2013): the GBD 2013 Study. Neuroepidemiology. 2015;45(3):230-6.

34. Fainzang S, Salem G, Rican S, Jougla E. Atlas de la santé en France, vol. 1 : Les causes de décès. [compte-rendu]. Sciences sociales et santé. 2001;19(2):113-5.

35. Coldefy M, Com-Ruelle L, Lucas-Gabrielli V, Marcoux L. Les distances d'accès aux soins en France métropolitaine au 1er janvier 2007: IRDES2011.

36. Evain F. À quelle distance de chez soi se fait-on hospitaliser ? Etudes et résultats DREES. février 2011;754.

37. Pedigo A, Aldrich T, Odoi A. Neighborhood disparities in stroke and myocardial infarction mortality: a GIS and spatial scan statistics approach. BMC Public Health. 2011;11:644.

38. Pedigo A, Seaver W, Odoi A. Identifying unique neighborhood characteristics to guide health planning for stroke and heart attack: fuzzy cluster and discriminant analyses approaches. PLoS One. 2011;6(7):e22693.

39. Combier E, Charreire H, Le Vaillant M, Michaut F, Ferdynus C, Amat-Roze $J M$, et al. Perinatal health inequalities and accessibility of maternity services in a rural French region: closing maternity units in Burgundy. Health Place. [Research Support, Non-U.S. Gov't]. 2013;24:225-33.

40. Handschu R, Wacker A, Scibor M, Sancu C, Schwab S, Erbguth F, et al. Use of a telestroke service for evaluation of non-stroke neurological cases. J Neurol. 2015;262(5):1266-70.

41. MasjuanVallejo J. Stroke unit: the best treatment for stroke patients. Neurologia. 2009;24(5):285-7.

42. Grimaud O, Bejot Y, Heritage Z, Vallee J, Durier J, Cadot E, et al. Incidence of stroke and socioeconomic neighborhood characteristics: an ecological analysis of Dijon stroke registry. Stroke. 2011;42(5):1201-6.

43. Grimaud O, Leray E, Lalloue B, Aghzaf R, Durier J, Giroud M, et al. Mortality following stroke during and after acute care according to neighbourhood deprivation: a disease registry study. J Neurol Neurosurg Psychiatry. 2014:85(12):1313-8.

44. Vigneron E. Territorial and social healthcare inequalities in France. Bull Acad Natl Med. 2012;196(4-5):939-52.

45. Ouedraogo S, Dabakuyo-Yonli TS, Roussot A, Dialla PO, Pornet C, Poillot $\mathrm{ML}$, et al. Breast cancer screening in thirteen French departments. Bull Cancer. 2015;102(2):126-38

46. Sudlow CL, Warlow CP. Comparing stroke incidence worldwide: what makes studies comparable? Stroke. 1996;27(3):550-8.

\section{Submit your next manuscript to BioMed Central and we will help you at every step:}

- We accept pre-submission inquiries

- Our selector tool helps you to find the most relevant journal

- We provide round the clock customer support

- Convenient online submission

- Thorough peer review

- Inclusion in PubMed and all major indexing services

- Maximum visibility for your research

Submit your manuscript at www.biomedcentral.com/submit
() Biomed Central 